\title{
EGG RETRIEVAL BY TRUMPETER SWANS
}

PAIGE C. MILLER, Idaho State University, Department of Biological Sciences, Pocatello, Idaho 83209; paigemiller@isu.edu

DAVID J. DELEHANTY, Idaho State University, Department of Biological

Sciences, Pocatello, Idaho 83209; daviddelehanty@isu.edu

The Trumpeter Swan (Cygnus buccinator), endemic to North America and its largest species of waterfowl, approached extinction in the 1930s (Banko 1960). But by 2015 , following nearly a century of conservation, its population had rebounded to some 63,000 wild birds (Groves 2017). Enhanced population size has provided increased opportunity for scientific study, and previously unreported behaviors now are being observed. Here we report egg retrieval-the act of a bird moving eggs from outside the nest bowl into the nest bowl-by nesting Trumpeter Swans for the first time. Egg retrieval is an important behavior that serves to restore reproductive opportunity after disturbance at the nest.

Trumpeter Swans breed in temperate lakes and marshes where they construct large nests of mounded vegetation surrounded by shallow water. Nest mounds are $1.2-3.6 \mathrm{~m}$ in diameter and $0.3-0.9 \mathrm{~m}$ in height. At the center of the mound, the swans form a nest bowl 25-40 $\mathrm{cm}$ in diameter and 10-20 cm deep (Mitchell and Eichholz 2019). Nest mounds, constructed by both members of a breeding pair (Hansen et al. 1971, Cooper 1979), consist of piled emergent and submerged aquatic vegetation, and occasionally grasses and sedges (Hansen et al. 1971, Mitchell and Eichholz 2019). Trumpeter Swans typically lay eggs at intervals of $\sim 36-48 \mathrm{hr}$ (Cooper 1979, Lumsden 2002), and clutch size averages 4-6 eggs (Mitchell and Eichholz 2019). As is typical of waterfowl, Trumpeter Swans initiate incubation just prior to completing a clutch (Banko 1960, Cooper 1979, Mitchell and Eichholz 2019) and incubate for 32-37 days (Banko 1960, Hansen et al. 1971, Mitchell and Eichholz 2019). Trumpeter Swans are sexually monomorphic, so sexing birds at a distance is difficult, but apparently the female is responsible for incubation almost exclusively (Banko 1960, Cooper 1979, Mitchell and Eichholz 2019).

Egg retrieval in the Graylag Goose (Anser anser) was described by Lorenz and Tinbergen (1938) in a classic paper conceptualizing instinctive behavior in birds. It has since been documented in many ground-nesting birds across a broad range of taxa (Poulsen 1953, Giesen 1978), including other waterfowl species (Sowls 1955, Prevett and Prevett 1973, Duncan 1984, Zaun and Weathers 2009). Among waterfowl, the adult retrieves eggs by standing on or near the nest bowl, reaching over the egg with its bill and drawing the egg toward its breast, sliding and rolling the egg into the nest bowl. Among the six extant species of swans (Eo et al. 2009), egg retrieval has been documented for the Mute Swan (Cygnus olor) and the Black Swan (Cygnus atratus), in both cases in captivity (Poulsen 1953). To our knowledge, ours is the first report of egg retrieval for the Trumpeter Swan or any swan in the wild.

The capacity to return eggs to the nest bowl after displacement can improve a bird's fitness when it rescues eggs that otherwise would fail. Disturbance of swan nests is probably frequent enough that response to disturbance has been shaped by natural selection, as in other waterfowl species (Duncan 1984, Zaun and Weathers 2009).

We observed egg retrieval by the Trumpeter Swan opportunistically while studying the thermal dynamics of the species' incubation during May and June 2020 at Red Rock Lakes National Wildlife Refuge in southwestern Montana. As part of the thermal study, we monitored six nests round the clock by video. The video systems were described by Bush (2018) in detail. Briefly, the cameras were mounted 1-2 $\mathrm{m}$ from swan nests and camouflaged; battery-powered recording equipment was housed 20-25 $\mathrm{m}$ from the cameras. 
We placed three auxiliary eggs for thermal logging at each of six swan nests. By auxiliary, we mean eggs that we added in addition to the natural clutch. Thermallogging auxiliary eggs consisted of natural, but evacuated, eggs from Trumpeter Swans, or Mute Swans when Trumpeter Swan eggs were unavailable, equipped with a Thermochron iButton (model DS1922L, Maxim Integrated Products, Sunnyvale, CA) temperature logger mounted to the inside surface of the eggshell (the hole created patched with smooth putty). At each nest, we simultaneously placed one auxiliary egg in the nest bowl with the natural clutch of eggs, one auxiliary egg on the surface of the nest mound $\sim 50-70 \mathrm{~cm}$ south of the edge of the nest bowl, and one auxiliary egg buried to a depth of $\sim 10-12 \mathrm{~cm}$ in the nest mound material and $\sim 50-70 \mathrm{~cm}$ south of the edge of the nest bowl. To anchor each auxiliary egg placed on the surface of the nest mound, we glued a $20-\mathrm{cm}$ length of wooden dowel to the egg to serve as an anchoring spike that we then inserted into the nest mound.

At each of the nests, a swan egg on the surface of the nest outside of the nest bowl elicited a strong and rapid response. After we placed the auxiliary eggs, adult swans initiated egg retrieval between $\sim 2$ and $23 \mathrm{~min}$ after returning to the nest (Table 1), usually before resuming incubation. While standing over or near the nest bowl, adults reached over exposed eggs with the bill and began attempting to draw exposed eggs toward their breasts, and thus toward the nest bowl in a manner similar to other waterfowl (Lorenz and Tinbergen 1938, Poulsen 1953, Sowls 1955). The birds' attempts to roll the eggs were hampered by the attached wooden dowels, however. Each adult took two to five short breaks from its efforts at retrieval to survey its surroundings, preen, or incubate the clutch. At all six nests the attending adult grasped the wooden dowel with the bill to dislodge it partially or fully from the nest vegetation. In five cases, swans detached dowels from the eggs with their bills and feet. In one case, a swan broke the dowel from the egg by wedging the egg and dowel with its body, leaving the auxiliary egg intact. After an auxiliary egg was detached from the dowel, the swan rolled the egg to the edge of the nest bowl, then rearranged the eggs already in the nest bowl before incorporating the new egg into the clutch.

Surprisingly, four swans also discovered the auxiliary eggs buried within the nest mound and successfully drew those auxiliary eggs up into the clutch. Swans appeared to discover the eggs while repairing the nest mound's surface that we had disturbed $(n=3)$ or during general nest maintenance $(n=1)$. The auxiliary eggs that we buried within the nest mounds were not anchored with wooden dowels. Swans were able to retrieve these auxiliary eggs more rapidly than the eggs anchored on the surface $(t=3.96, p=0.0042$; Table 1$)$. Egg-retrieval times for the unanchored auxiliary eggs buried within the nest mounds likely represent swans' natural efficiency in egg retrieval. The short latency (time elapsed between discovery of eggs outside the nest bowl and initiation of retrieval behavior) of the Trumpeter Swans in our experiment was consistent with other species, such as the White-tailed Ptarmigan (Lagopus leucura), which typically respond to displaced eggs immediately (Giesen 1978).

We video-documented Trumpeter Swans retrieving 10 swan eggs, nine Trumpeter Swan eggs and one similarly sized Mute Swan egg, all of which were placed $<1 \mathrm{~m}$ from the nest bowl, six on top of the nest mound and four buried within

TABLE 1 Mean Latency, Egg-Retrieval Times, and Number of Pauses of Trumpeter Swans Attempting to Retrieve Eggs Experimentally Placed at Six Nests

\begin{tabular}{lcc}
\hline Behavior & $\begin{array}{c}\text { Buried egg mean } \pm \text { SE } \\
(n=4)\end{array}$ & $\begin{array}{c}\text { Anchored egg mean } \pm \text { SE } \\
(n=6)\end{array}$ \\
\hline Latency time $(\mathrm{min})$ & $0.20 \pm 0.03$ & $3.38 \pm 0.25$ \\
Retrieval time $(\mathrm{min})$ & $3.44 \pm 0.20$ & $25.70 \pm 1.82$ \\
Number of pauses & $0.0 \pm 0.0$ & $3.0 \pm 0.2$ \\
\hline
\end{tabular}




\section{NOTES}

the mound. This propensity to retrieve eggs that were not their own indicates a strong instinct to rescue displaced eggs and perhaps could be a pathway for as yet undocumented nest parasitism as well. Further investigation of the effects of egg displacement (distance and relative timing) during incubation are needed to clarify the context of egg retrieval-behavior in the Trumpeter Swan.

We thank the U.S. Fish and Wildlife Service for permits and essential logistical assistance, with special thanks to Mike Bryant, Cortez Rohr, Kyle Cutting, Andrea Kristof, and Carl Mitchell (retired), and we thank Brenda Zaun for her helpful review. This work was funded through grants from Idaho State University's Biological Sciences Research Committee and Center for Environmental Research and Education.

\section{LITERATURE CITED}

Banko, W. E. 1960. The Trumpeter Swan: Its history, habits, and population in the United States. N. Am. Fauna 63; doi.org/10.5962/bhl.title.77381.

Bush, D. A. 2018. Incubation behavior and genetic attributes of Trumpeter Swans restored to Grays Lake National Wildlife Refuge. M.S. thesis, Idaho State Univ., Pocatello.

Cooper, J. A. 1979. Trumpeter Swan nesting behaviour. Wildfowl 30:55-71.

Duncan, D. C. 1984. Egg retrieval by Canada Geese: Apparent interspecific retrieval and tests of egg displacement. Auk 101:886-887; doi.org/10.2307/4086920.

Eo, S. H., Bininda-Emonds, O. R. P., and Carroll, J. P. 2009. A phylogenetic supertree of the fowls (Galloanserae, Aves). Zoologica Scripta 38:465-481; doi. org/10.1111/j.1463-6409.2008.00382.x.

Giesen, K. M. 1978. Egg retrieval by incubating White-tailed Ptarmigan. Auk 95:761-762.

Groves, D. J. 2017. The 2015 North American Swan Survey: A cooperative North American survey. U.S. Fish and Wildlife Service, Office of Migratory Bird Mgmt., Juneau, AK.

Hansen, H. A., Shepherd, P. E. K., King, J. G., and Troyer, W. A. 1971. The Trumpeter Swan in Alaska. Wildl. Monogr. 26.

Lorenz, K., and Tinbergen, N. 1938. Taxis and instinct in the egg rolling response of the Graylag Goose, in Instinctive Behaviour: The Development of a Modern Concept (C. H. Schiller, ed.), pp. 176-208. Internatl. Univ. Press, New York.

Lumsden, H. G. 2002. Hatchability of eggs from captive Trumpeter Swans. N. Am. Swans 31:2-4.

Mitchell, C. D., and Eichholz, M. W. 2019. Trumpeter Swan (Cygnus buccinator), in Birds of the North America (P. G. Rodewald, ed.), version 3.0. Cornell Lab Ornithol., Ithaca, NY; doi.org/10.2173/bow.truswa.01.

Poulsen, H. 1953. A study of incubation responses and some other behaviour patterns in birds. Videns. Medd. Dansk Naturh. Foren. 115:1-131.

Prevett, J. P., and Prevett, L. S. 1973. Egg retrieval by Blue Geese. Auk 90:202-204.

Sowls, L. K. 1955. Prairie Ducks: A Study of Their Behavior, Ecology and Management. Univ. Nebr. Press, Lincoln.

Zaun, B. J., and Weathers, W. W. 2009. Egg retrieval by the Hawaiian Goose after attempted predation by a cat. W. Birds 40:39-42. 